Research Article

\title{
Optimal Reservoir of Small Reservoirs by Optimization Techniques on Reservoir Simulation Model
}

\author{
Krit Sriworamas $\mathbb{D}^{1},{ }^{1}$ Anongrit Kangrang $\mathbb{D}^{2},{ }^{2}$ Teerawat Thongwan $\mathbb{D D}^{2}$ \\ and Haris Prasanchum $\left.{ }^{3}\right)^{3}$ \\ ${ }^{1}$ Faculty of Engineering, Ubonratchathani University, Ubonratchathani 34190, Thailand \\ ${ }^{2}$ Faculty of Engineering, Mahasarakham University, Kantarawichai, Mahasarakham 44150, Thailand \\ ${ }^{3}$ Faculty of Engineering, Rajamangala University of Technology, Isan Khon Kaen Campus, Muang, Khon Kaen 40000, Thailand
}

Correspondence should be addressed to Anongrit Kangrang; anongrit.k@msu.ac.th

Received 3 January 2021; Revised 21 May 2021; Accepted 27 May 2021; Published 16 June 2021

Academic Editor: Tayfun Dede

Copyright (c) 2021 Krit Sriworamas et al. This is an open access article distributed under the Creative Commons Attribution License, which permits unrestricted use, distribution, and reproduction in any medium, provided the original work is properly cited.

Reservoir rule curves are essential rules for store activity. This investigation connected the Genetic Algorithm, Firefly Algorithm, Bat Algorithm, Flower Pollination Algorithm, and Tabu Search Algorithm associated with the store reproduction model to look through the ideal supply standard bends, utilizing the Huay Ling Jone and Huay Sabag supplies situated in Yasothorn Province, Thailand, as the contextual investigation. Memorable inflow information of the two repositories were utilized in this investigation, and 1,000 examples of engineered inflows of stores were utilized to recreate the repository activity framework for assessing the acquired principle bends as displayed as far as water circumstances. Circumstances of water lack and abundance water appeared as far as the recurrence extent and length. The outcomes demonstrated that GA, FA, BA, FPA, and TS associated with the reservoir simulation model could give the ideal principle bends which better moderate the drought and flood circumstances contrasted and current guideline bends.

\section{Introduction}

Flood and drought situations are expanding in numerous districts in view of high populace development, monetary extension, land use change, and environmental change; therefore, to avoid the circumstances described above, water resource management must be improved. Similarly, the demand and supply management sites of water resource management are considered a solution to these serious problems; however, in order to save time and money, a nonconstruction method is required; for example, to escalate the effectiveness of irrigation, to engage public participation, and to reform reservoir operation management. In particular, reservoir operation was based on reservoir rule curves. This can be considered a widely used practice for the management and allocation of water resources from reservoirs [1]. It is necessary as guidelines for water release and storage through the long-term operation conducted monthly under the inflow conditions for the reservoir and downstream demand criteria [2-4].

In general, water allocation from a reservoir can be considered a complex and nonlinear problem due to a large number of conditions and variables. However, from the past ten years, improvements have been made to reservoir rule curves to address complex problems using the optimization technique, which is widely studied $[5,6]$, because it provides quantitative results consistent with the hydrological change situation, including its application in water allocation to reduce economic losses caused by pollution $[7,8]$. It can also be used as a tool for decision support systems (DSS) in finding the optimal land use in relation to groundwater vulnerability [9].

At first, numerous improvement systems have been connected to locate the ideal reservoir rule curves; for 
instance, Dynamic Programming (DP), Simulated Annealing Algorithm (SA), Particle Swam Optimization (PSO), Cuckoo Search (CS), and Tabu Search (TS) [10-23]. Furthermore, those obtained principles' rule curves were viably connected by looking through conditions, for example, historic inflow data, water request in downstream, standard working, and smoothing capacity rule just as the target elements of looking through methodology. In any case, most past strategies have been connected to locate the ideal reservoir rule curves of just the enormous repositories in Thailand (storage volume higher than $100 \mathrm{MCM}$ ). These days, there are numerous new viable improvement methods that have not yet been connected to locate the ideal reservoir rule curves with little supply. The mentioned techniques include Genetic Algorithm (GA), Firefly Algorithm (FA), Bat Algorithm (BA), Flower Pollination Algorithm (FPA) and Tabu Search (TS) that are effective alternative optimization techniques [24-36]. These optimization techniques have evolved from an evolutionary algorithm into the metaheuristic optimization algorithm and swarm intelligence, which are inspired by biological evolution and natural systems. For example, GA uses the concept of solution operators such as reproduction and mutation. FA has a concept from the firefly's flashing behavior to attract other fireflies to fly around them and form small groups. The concept of BA mimics the behavior of bats that use sonar for navigation and echolocation. Similarly, FPA draws inspiration from self-pollination and cross pollination by other plants. In addition, for the TS algorithm, a data structure is used to remember solved problems and know the accepted answers, where the model will not resolve the same problem again or the problem has a limited time to resolve.

This study thus proposed the GA, FA, BA, FPA, and TS associated with the reservoir simulation model to find the optimal reservoir rule curves of small reservoirs in Thailand. The Huay Ling Jone and Huay Sabag reservoirs in Yasothorn Province were selected as the case study.

\section{Methodology}

2.1. Reservoir Operation Model. The system of reservoir operation typically comprises of the accessible water regulated by utilizing the water balance ideas and water requests from downstream; then, the month-to-month discharged water is evaluated by thinking about the month-to-month accessible water with discharge criteria, working arrangements, and repository guideline bends. For this examination, the store task model was made after the idea of the water equalization to be worked under the standard working strategy as communicated in Figure 1 and following equation [37]:

$$
\begin{aligned}
W_{\tau} & =S_{\tau-1}+Q_{\tau}+P_{\tau}-E_{\tau}, \\
S_{\tau} & =W_{\tau}-R_{\tau},
\end{aligned}
$$

where $W_{\tau}$ is the accessible water between month $\tau$ ( $\tau=1$ to 12 represents January to December), $S_{\tau}-_{1}$ is the maintained water at the end of month $t-1, Q_{\tau}$ is the reservoir's monthly inflow, $P_{\tau}$ is the precipitation over the reservoir, $E_{\tau}$ is the average value of the evaporation loss, $S_{\tau}$ is the maintained water at the end of month $\tau, R_{\tau}$ is the water release during month $\tau$, and $D_{\tau}$ is the water demand from the reservoir during month $\tau$. Released water from the reservoir simulation model $\left(R_{\tau}\right)$ was used for a calculation of the water shortage and excessive water release circumstances in which these circumstances were used for calculating the objective function of the searching process (average annual shortage per year).

\subsection{The Objective Functions for Searching Optimal Rule} Curves. Currently, the hydrological system has been impacted by climate change, inflow to reservoirs, and water allocation to downstream areas differently than in the past. For example, in 2012-2013, there was a severe drought throughout the country, while in 2016, repeated floods caused great damage, especially in the northeastern region of Thailand. Therefore, water resource management of reservoirs in Thailand focuses on two main tasks: (i) providing sufficient water during the drought period and (ii) preventing flooding during the rainy season. Consequently, the evolution of optimal rule curves for reservoirs in this study would like to focus on two objective functions: (1) minimum water shortage, as shown in equations (3) and (4), and (2) minimum water exceeding release, as shown in equations (5) and (6) as follows:

$$
\begin{aligned}
& \text { Min } Z(X i)=\left(\frac{1}{n} \sum_{v=1}^{n} S h_{v}\right), \\
& \text { if } R_{\tau}<D_{\tau}, \\
& \text { Then } S h_{v}=\sum_{\tau=1}^{12}\left(D_{\tau}-R_{\tau}\right), \\
& \text { Else } S h_{v}=0,
\end{aligned}
$$

where $Z$ is the minimum average volume of insufficient water per year, $n$ is the whole magnitude of examined years, $S p_{V}$ is the magnitude of water shortage during years $v$ (year in which overflows do not meet $100 \%$ of the objective condition), and $i$ is the iteration rounds. Later, the finding system is extended on the circumstance that the completion criterion is conceded. This completion norm is the optimum objective function with a negligible change (slightly less than $0.10 \mathrm{MCM})$.

The minimum average volume of release excess water per year $(U)$ is located as the second objective function of the considering procedure subject to the restrictions in the simulation model as illustrated in the following equations:

$$
\begin{aligned}
& \operatorname{Min} U(X i)=\left(\frac{1}{n} \sum_{v=1}^{n} S p_{v}\right), \\
& \text { if } R_{\tau}>D_{\tau}, \\
& \text { then, } S p_{v}=\sum_{\tau=1}^{12}\left(R_{\tau}-D_{\tau}\right), \\
& \text { else, } S p_{v}=0,
\end{aligned}
$$




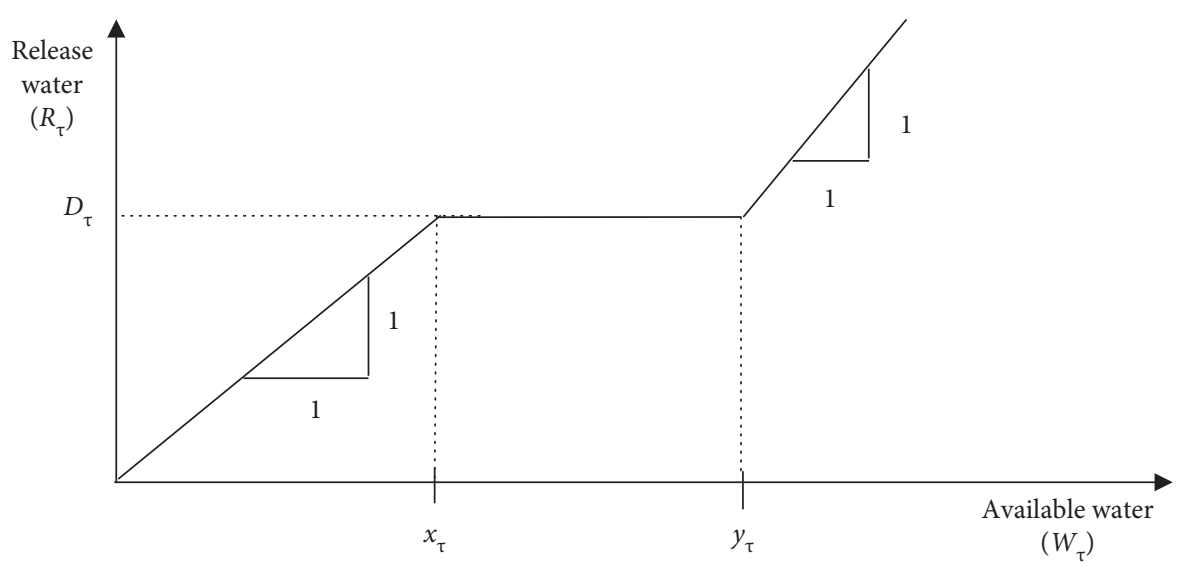

Figure 1: Standard operating rule.

where $n$ is the total magnitude of examined years, $S p_{V}$ is the volume of discharge excess water during years $v$ (year in which discharge excess water are higher than the objective condition), and $i$ is the iteration rounds.

\subsection{Applying GA, FA, BA, FPA, and TS for Searching Optimal} Rule Curves. The main idea of the paper was to find the optimal monthly storage volume of the reservoir in relation to input factors (e.g., inflow, precipitation, and hydrologic conditions) and output factors (e.g., water allocation to downstream areas) over a 12-month period in a year. The search for the most appropriate response is based on the optimization techniques of each type, integrating the link with the reservoir simulation model, with the aim of comparing the results, finding the strengths, observations of each technique for the development of optimal reservoir rule curves, and their applications. They demonstrated that the choice factors (ideal standard bends, 24 choice factors comprising of 12 esteems from the upper bound and another 12 esteems from lower bound circumstances) of each inquiry were made from the beginning advance. At that point, these factors were utilized in the store recreation model for activities of the framework under the conditions relating to every repository, for example, recorded inflow information, water request information, and other physical trademark supply. In the wake of running the model, the month-tomonth discharge waters were acquired, and these were utilized to compute the target capacity of the scanning process for assessing and creating new choice factors. Next, the supply reproduction model was run again until the stop condition was met. This system was rehashed until 24 estimations of the standard bends were proper. The utilization of these streamlining strategies (GA, FA, BA, FPA, and TS) to associate with the repository recreation model for looking through ideal guideline bends is descripted as follows.

2.3.1. GA Optimization for Searching Rule Curves. In the GA technique used to find for optimal rule curves, it relies on an encoding scheme to convert a decision variable into a chromosome, performing selection, crossover, and mutations [38]. After this procedure, the genetic action generates a new chromosome. Each decision variable is defined as an average monthly water retention value, which is defined as an upper margin and lower margin, subsequently calculating the first set of chromosomes in the initial population (24 decision variables comprising 12 values from the upper margin and 12 values from the lower margin situation). The amount of released water is recomputed by the reservoir model associated with the GA algorithm. Then, the discharged water is used to define the objective function to evaluate the suitability of GA. Through the reproduction process, the point values of the control curve are regenerated in the next generation. At this stage, the calculation is duplicated until the value of 24 points of rule curves' answers is appropriate. The GA associated with the reservoir simulation model can be illustrated, as shown in Figure 2.

2.3.2. FA Optimization for Searching Rule Curves. The principle FA is based on the communication behavior of individual firefly populations that seek to find the light through the attraction of the brightest fireflies [39]. The intensity of the emitted light determines the attraction. This is usually determined by the fitness value obtained from the objective function (minimum water shortage and minimal overflowing, respectively). Figure 3 illustrates the process of finding the optimal reservoir rule curves using the FA technique. It can be explained that the initial part defines the firefly population boundaries from the distance and dimension between two fireflies $\left(X_{i}\right.$ and $X_{j}$ and $x_{i d}$ and $x_{j d}$, respectively) [40] as 12 upper bound points and 12 lower bound points, which totaled 24 points. Then, the reservoir simulation model was associated to the population conditions with the required objective function, and a computational process was started to find out. Next, the results from the first set of computations (the best 12 rule curve points in this computational cycle) are considered as a more concentrated light that attracted the new firefly population to converge towards the response region of the new rule curves' point series. The answer obtained from each calculation is the optimal rule curve point, which is updated until the required number of rounds of calculations are completed and satisfied with the answer. 


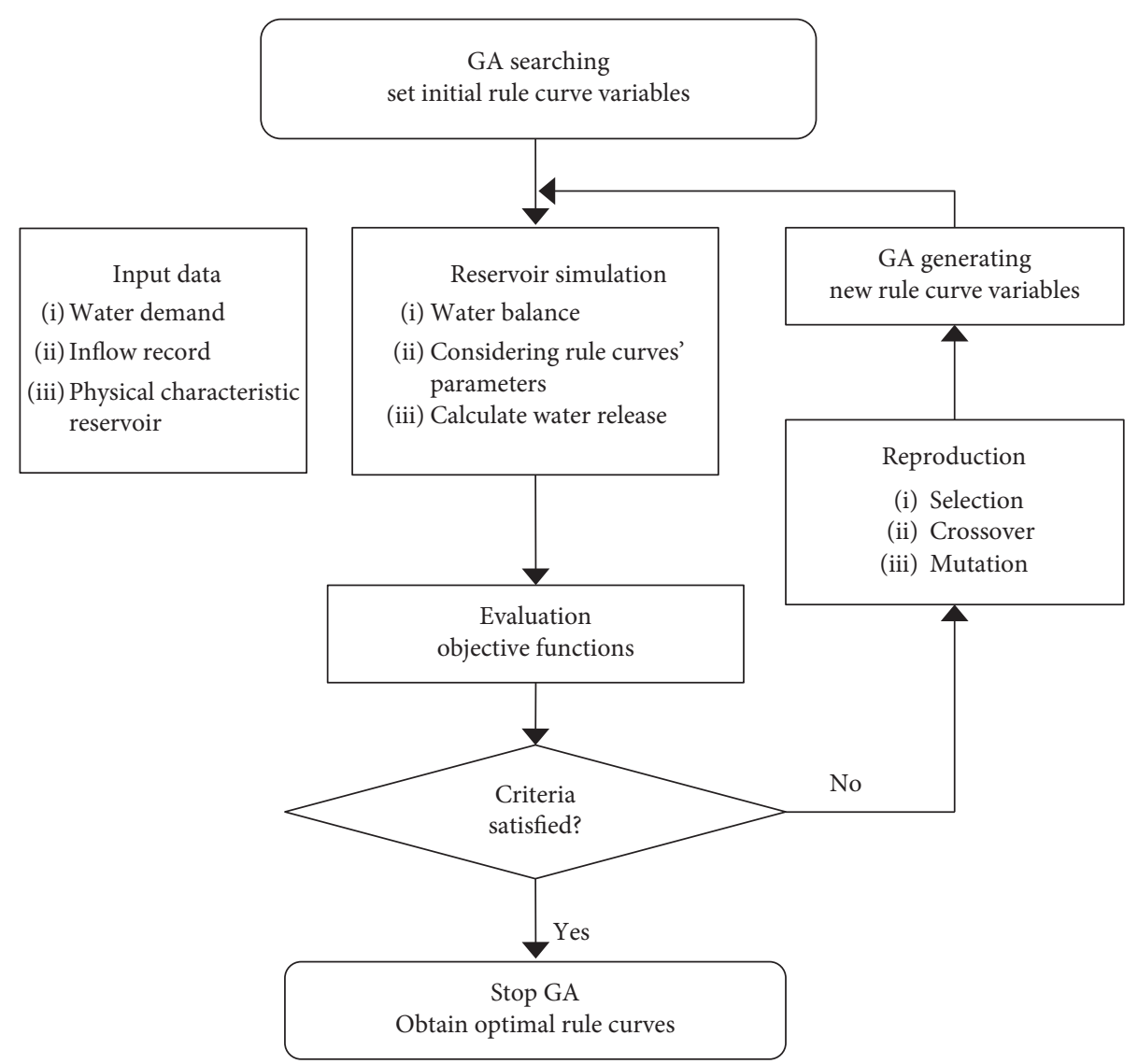

FIGURE 2: Genetic algorithm connecting reservoir simulation for searching rule curves.

2.3.3. BA Optimization for Searching Rule Curves. To compute the optimal rule curves using the BA technique, there is a first step consisting of three condition definitions: (i) defining a sample of the bat population; here, the possible amount of retained water between the upper and lower bounds in each month, (ii) determining the initial response set derived from the echolocation of the bats to the target to reduce the search distance as much as possible to the default, and (iii) in the search-answer phase, an algorithm was assigned to mimic the behavior of the bat's random flight at speed $\left(v_{i}\right)$ at $\left(x_{i}\right)$ position with different frequencies from minimum $\left(f_{\min }\right)$ to maximum $\left(f_{\max }\right)$ or using different wavelengths $(\lambda)$ and loudness $(A)$, and the wavelength (or frequency) of the emitted pulses can be adjusted automatically. In addition, the impulse delivery rate $(r)$ is related to the target proximity range [41], which is the best rule curves' point of 12 months in this round of calculations. Then, the first calculated answer set is considered in the context of the reservoir simulation model process and the objective function. However, if the answer in each round does not meet the criteria of the objective function, the algorithm process returns to the initial stage and finds and updates the answer until satisfactory and consistent results are obtained. As described previously, a schematic for the application of BA techniques to find the optimal rule curves is shown in Figure 4.
2.3.4. FPA Optimization for Searching Rule Curves. The concept of FPA was inspired by the nature of flower pollination, which has four rules of conduct: (i) global pollination consists of live pollination and cross pollination in which the pollen has a movement pattern that follows Levy flight, (ii) local pollination is considered as self-pollination and abiotic pollination, (iii) the stability of flowers by pollinators is equivalent to the reproduction probability, which is proportional to the similarity of the two flowers involved in the pollination process, and, (iv) the interaction of global and local pollination can be controlled by the alternation probability [42].

Figure 5 shows a process diagram of applying FPA to find the optimal rule curves for a reservoir. Consistent with the previous explanation, the first process is to determine the initial population based on the physical factor data of the reservoir (e.g., reservoir size, water surface area, precipitation, amount of water from the hydrologic system), determining the maximum number of rounds required for the calculations. This includes the extent of the search for the answer (the upper and lower bounds of each month's optimal rule curve point) and the initial population generated by the random solution. Then, the algorithm explores the answer corresponding to the random solution and selects the best results for this population. Next, the results obtained from the previous steps are treated as a path to the 


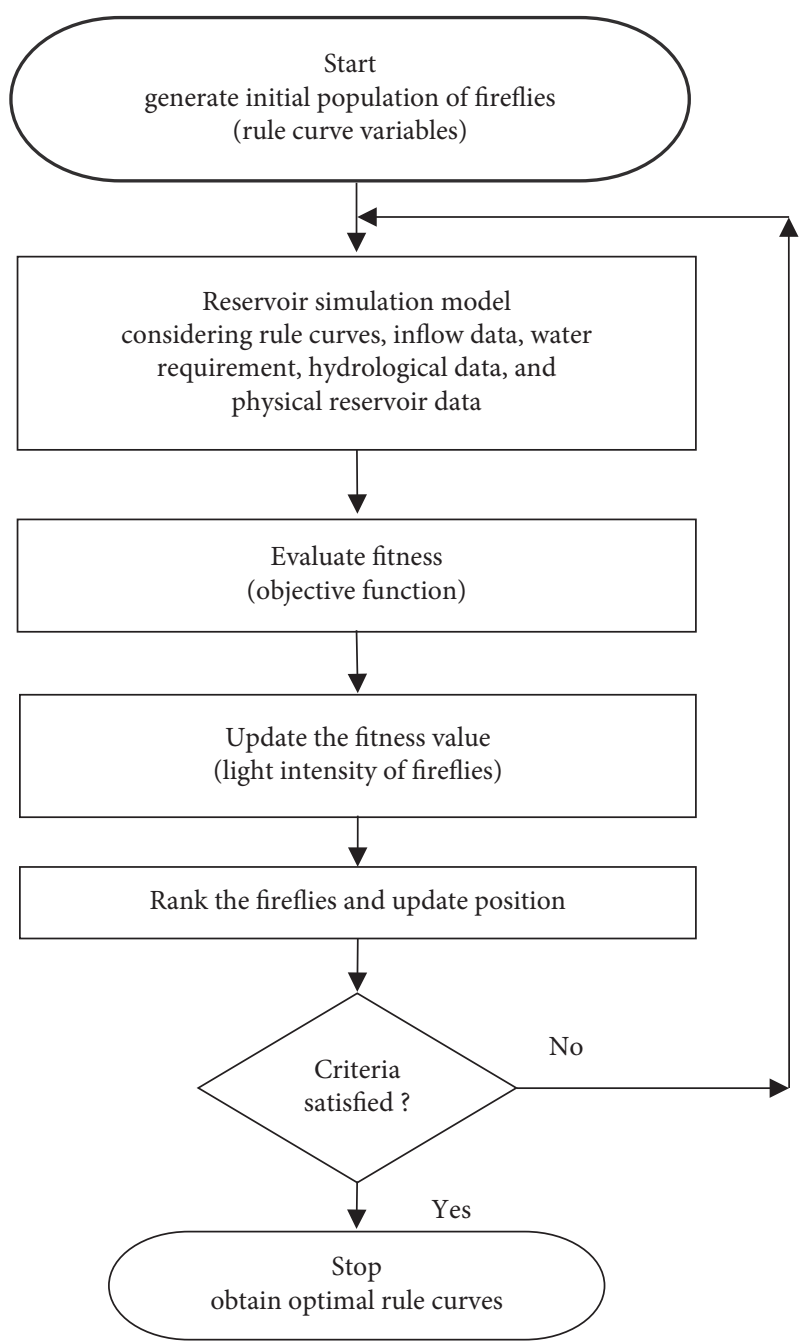

Figure 3: Firefly Algorithm and reservoir simulation model for searching optimal rule curves.

computations to find answers in the form of global pollination with the directional movement of Levy Flight. The answers obtained from this round of calculations for the best control curve points for each month were linked to the reservoir simulation model. Then, a process is performed to evaluate the answer obtained according to the constraints with the created objective function. Finally, the algorithm terminates the calculation only when it obtains the optimal rule curves result with satisfactory evaluation results.

2.3.5. TS Optimization for Searching Rule Curves. The following steps describe how to use the TS algorithm in conjunction with the reservoir simulation model. The TS generates a random preliminary set $\left(x_{1}, x_{2}, \ldots, x_{n}\right)$ within the free space as the possible value between the dead maintain capacity and the usual water level of the reservoir under consideration in the first phase. The potential distance is the difference between the dead maintain capacity and the ordinary water level of the reservoir. The method then

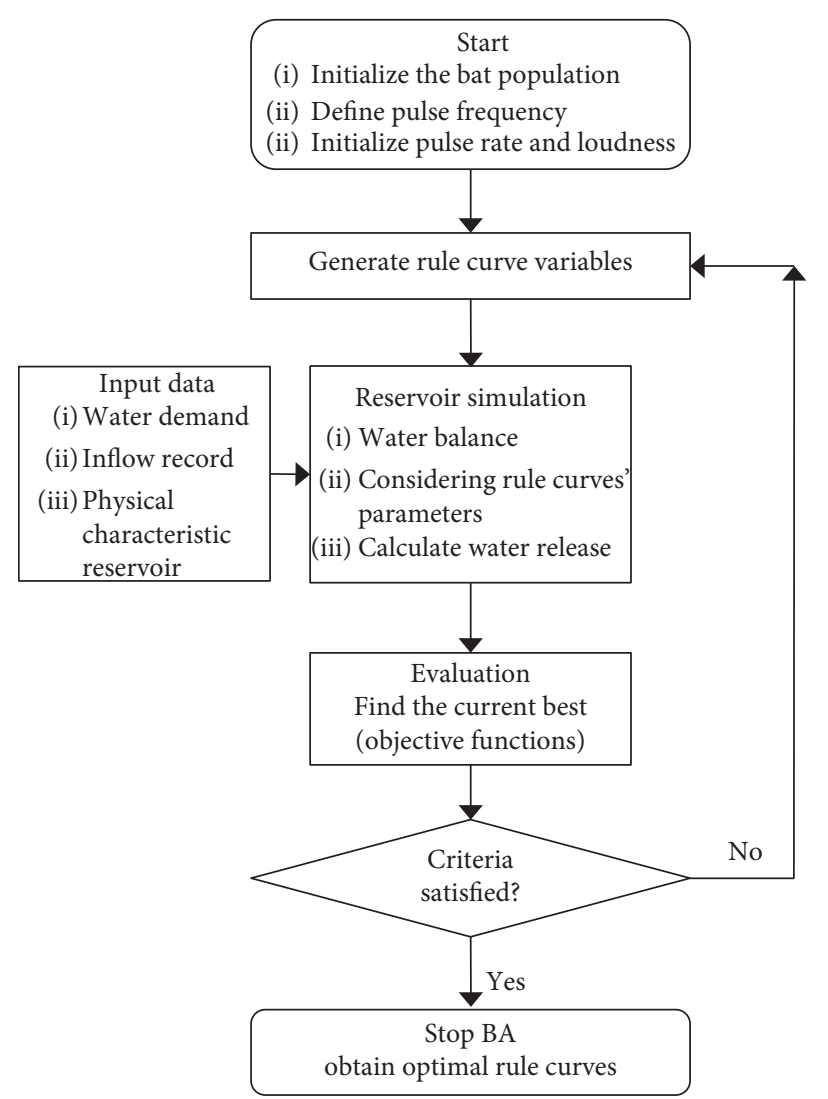

FIgURE 4: Bat Algorithm and reservoir simulation model for searching optimal rule curves.

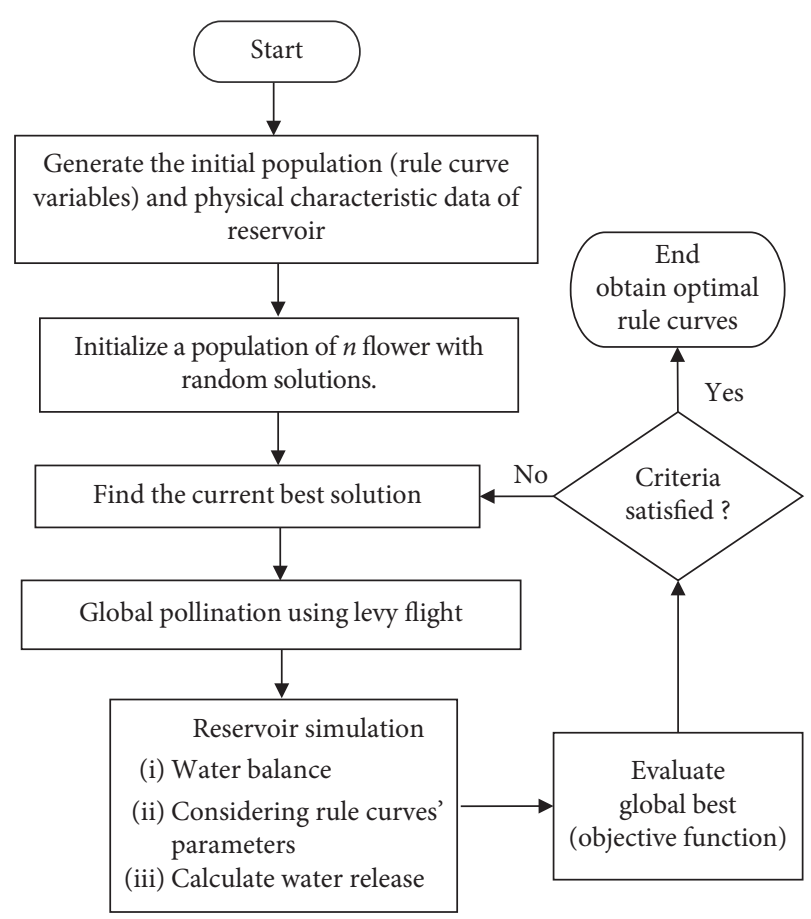

FIgUre 5: Flower Pollination Algorithm connecting reservoir simulation for searching rule curves. 
considers 24 decision factors representing the 12 values from the upper margin and 12 values from the lower margin, respectively, and the potential outcomes of $i^{\text {th }}$ repetitions, as $x_{i}=\left[x_{i 1}, x_{i 2}, \ldots, x_{i 24}\right]^{\mathrm{T}}$. In this round of computation, the processed and agreed upon answer set is stored in the tabu list [43]. To complete the process, the newly created rule curve solution set is connected to the reservoir model. Finally, the 24 points of rule curves' solution sets for each round of computation are connected to the monthly reservoir water released from the reservoir model. Figure 6 shows the algorithm TS in conjunction with the reservoir model.

2.4. Illustrative Application of Proposed Models. In this study, we selected the irrigation project in Yasothon Province, located in the northeast of Thailand to represent the study area. For the representative of the reservoirs in the study area, two reservoirs were selected, the Hauy Ling Jone Reservoir and the Hauy Sabag Reservoir, a small reservoir (collected less than $100 \mathrm{MCM}$ ) in the Moon River basin's tributaries. The study area and schematic diagram are described in Figures 7 and 8. Geographically, the summary area of the Huay Sabag is approximately $52.00 \mathrm{~km}^{2}$ with a total cumulative annual average runoff of about $22.4 \mathrm{MCM}$ during 1996 to 2017 (22 years), and its normal storage capacity is $30.03 \mathrm{MCM}$.

The Huay Ling Jone Reservoir has an irrigation area of $19.88 \mathrm{~km}^{2}$, full storage capacity of $21.06 \mathrm{MCM}$, and dead storage capacity of $0.40 \mathrm{MCM}$. The historic inflow data records of the Huay Ling Jone Reservoir were recorded from 1994 to 2017 (24 years). In essence, the demand for downstream areas includes consumption, irrigation, flood prevention, water supply, and ecological conservation. The historic inflow data records of both reservoirs are presented in Figure 9.

\section{Results and Discussion}

3.1. Optimal Rule Curves. The month-to-month noteworthy inflow information from the most recent 24 years (1994-2017), month-to-month information of dissipation, precipitation, water system, household and modern water requests, and month-to-month ecological protection of the Huay Ling Jone were imported for handling in the GA, FA, $\mathrm{BA}, \mathrm{FPA}$, and TA methods associated with the repository reenactment model, and after each one of those models were run, the ideal guideline bends were at long last acquired. The information from Huay Sabag repository were additionally brought into the proposed models before they were kept running along these lines as the Huay Ling Jone supply to get the bends. The ideal guideline bends of the Huay Ling Jone repository and the Huay Sabag store now are exhibited in Figures 10 and 11 separately. They demonstrate that the examples of all standard bends were normally comparable because of the inflow impact and the equivalent looking conditions [44]. Notwithstanding, the lower guideline bends existing in the Huay Ling Jone supply were not exactly the bends of GA, FA, BA, FPA, and TA principle bends, particularly during May to August. Although the acquired lower standard bends of GA, FA, BA, FPA, and TA from the Huay Sabag store were higher than the current principle bends, these standard bends could be utilized for an assessment of the model's effectiveness on the reservoir.

3.2. Efficiency of the Obtained Rule Curves. Tables 1 and 2 demonstrate the circumstances of water deficiency and too much discharged water of the Huay Ling Jone repository utilizing the notable inflow of the most recent 24 years and the engineered inflow of 1,000 examples individually. They demonstrate that the normal water lack and the recurrence of water deficiency by utilizing RC3-FA principle bends were the lowest (1.917 MCM/year and 2.217 $\pm 0.932 \mathrm{MCM} /$ year) as compared with the other standard bends that considered both historic inflow and synthetic inflow cases.. These were corresponding to the objective function of the searching. Moreover, the rule curves of RC3-FA could mitigate excessive water better than other rule curves in both of those two scenarios (6.214 MCM/year and 7.299 $\pm 1.810 \mathrm{MCM} /$ year).

Tables 3 and 4 present the situations of water shortage and excessively released water of the Huay Sabag reservoir using the historical inflow of the last 22 years and the synthetic inflow of 1,000 samples, respectively. They demonstrate that the average water shortages of all rule curves were zero in both of the historical inflow and synthetic inflow cases. Thus, these situations due to the total inflow were too much demanding than the total water demand. Additionally, the study results expressed that the situation of excessive water by using the rule curves from GA, FA, BA, FPA, and TA techniques was lower than their existing rule curves in both of historic inflow and synthetic inflow scenarios.

\subsection{Efficiency of the Obtained Rule Curves of the Huay Sabag} Reservoir under 30\% Increased Water Demand. The productivity of the acquired standard bends from the Hual Sabag repository was assessed again by $30 \%$ expanded water request in the downstream sites. Similar states of the repository reproduction models were utilized to recreate the supply framework with the goal that these assessments were performed in both noteworthy inflow situation and manufactured inflow situations, and its last outcomes are displayed in Tables 5 and 6 .

The outcomes demonstrated that the water deficiency circumstances at Huay Sabag utilizing the current standard bends were not as much as utilizing the acquired guideline bends of GA, FA, BA, FPA, and TA, as the complete inflow was higher more than the all requirement. Moreover, over the top water circumstance utilizing the standard bends structure GA, FA, BA, FPA, and TA strategies was still lower than utilizing the current guideline bends in both historic inflow and synthetic inflow situations.

From the previously mentioned, the GA, FA, BA, FPA, and TA methods could be compelling and material for finding the ideal principle bends for the supply of an extreme water circumstance. 


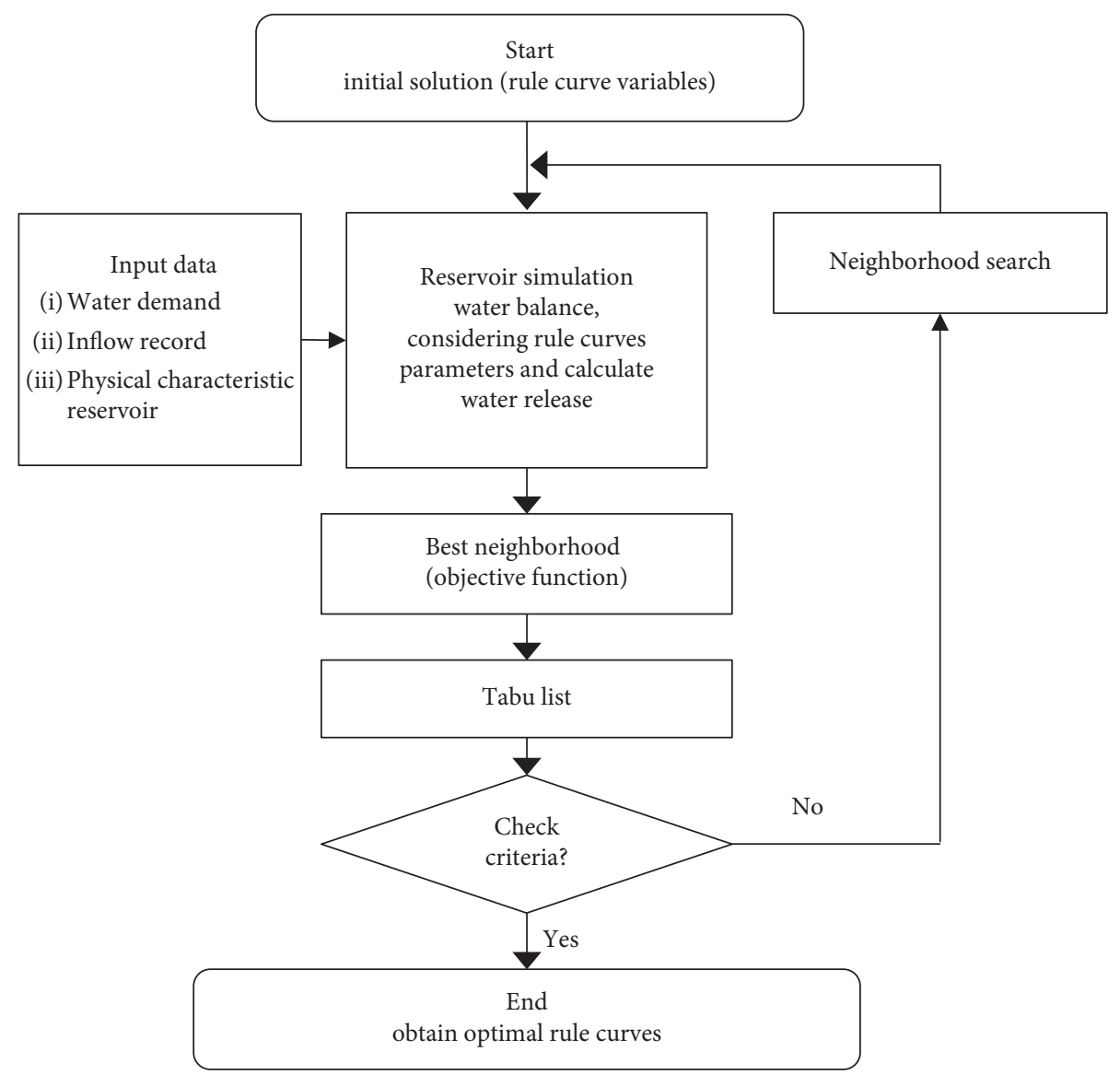

Figure 6: Tabu Search Algorithm connecting reservoir simulation for searching rule curves.

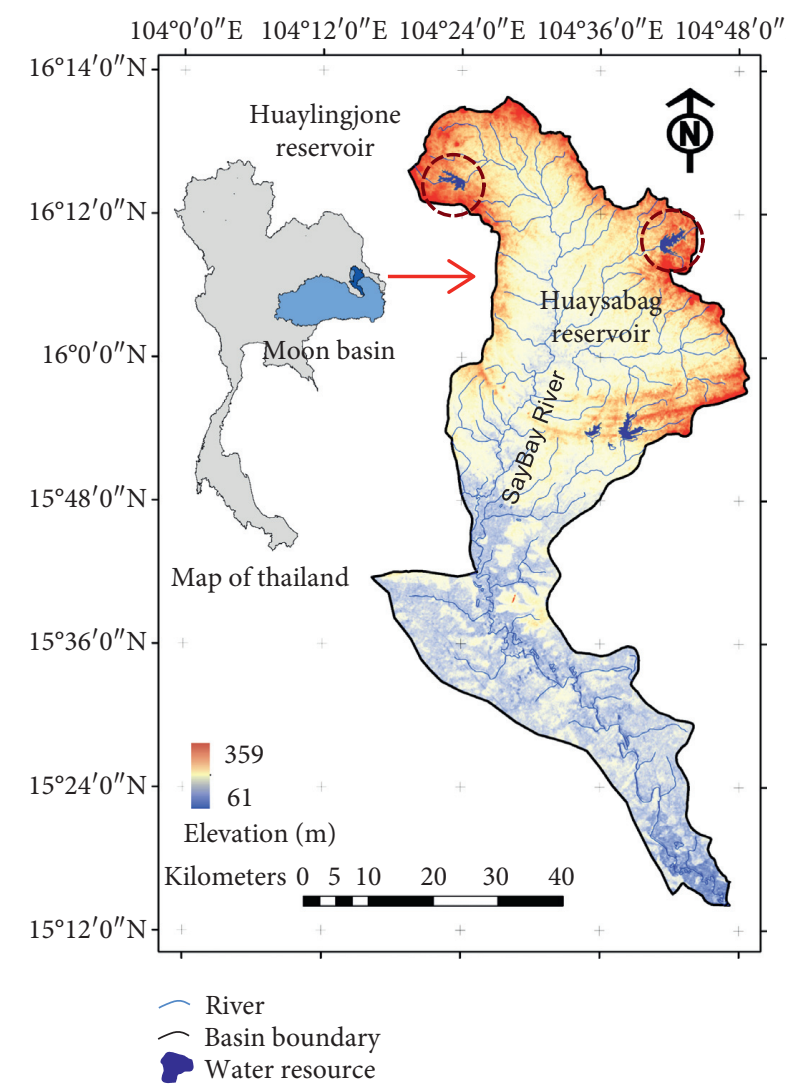

Figure 7: Location of the Hauy Ling Jone reservoir and the Huay Sabag reservoir. 


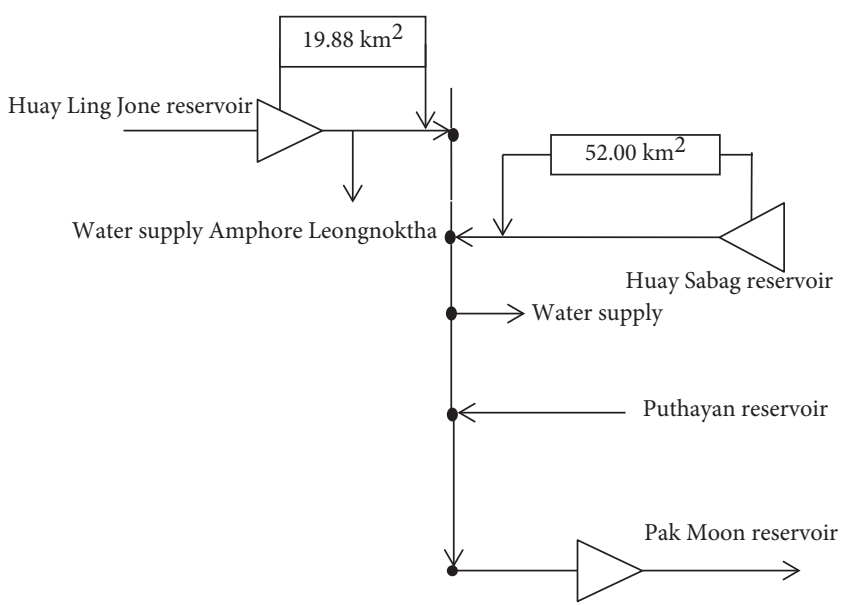

$$
\begin{aligned}
& \triangle \text { Reservoir } \\
& \longrightarrow \text { Flow direction }
\end{aligned}
$$

FIGURE 8: Schematic diagram of the Hauy Ling Jone and the Huay Sabag reservoir.

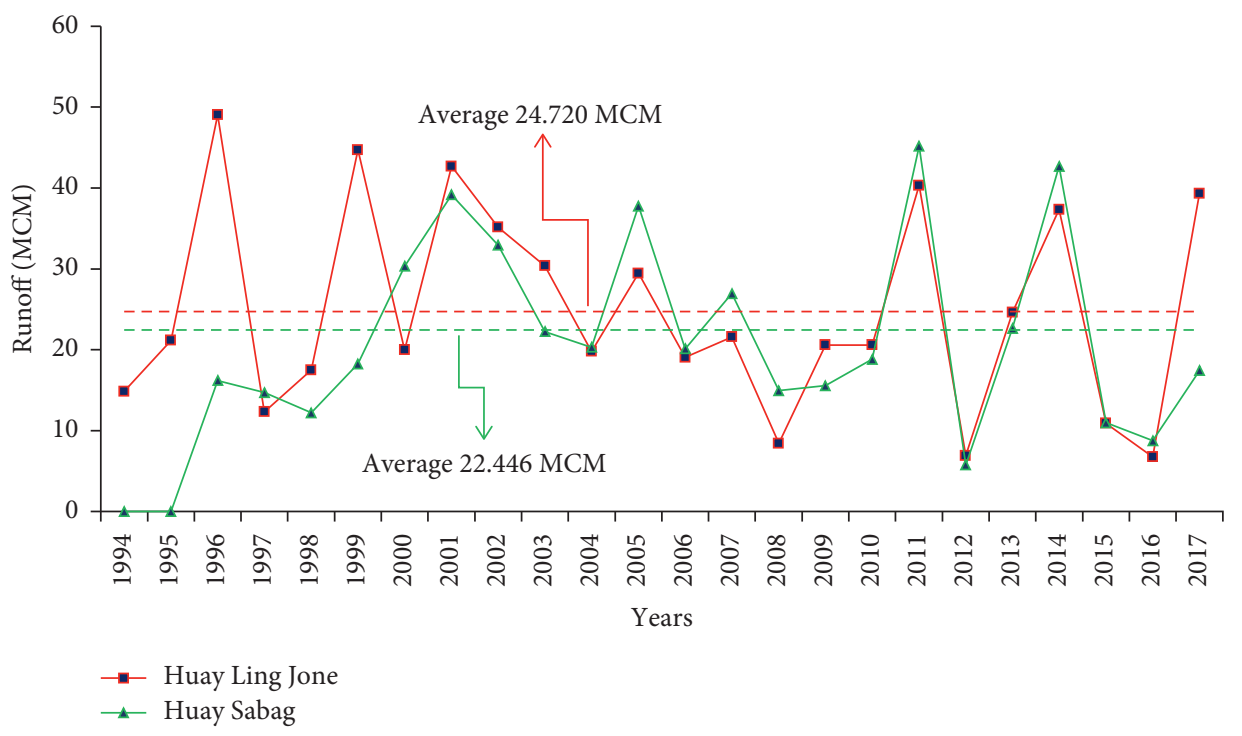

Figure 9: Historic inflow to the Huay Ling Jone and the Huay Sabag reservoirs.

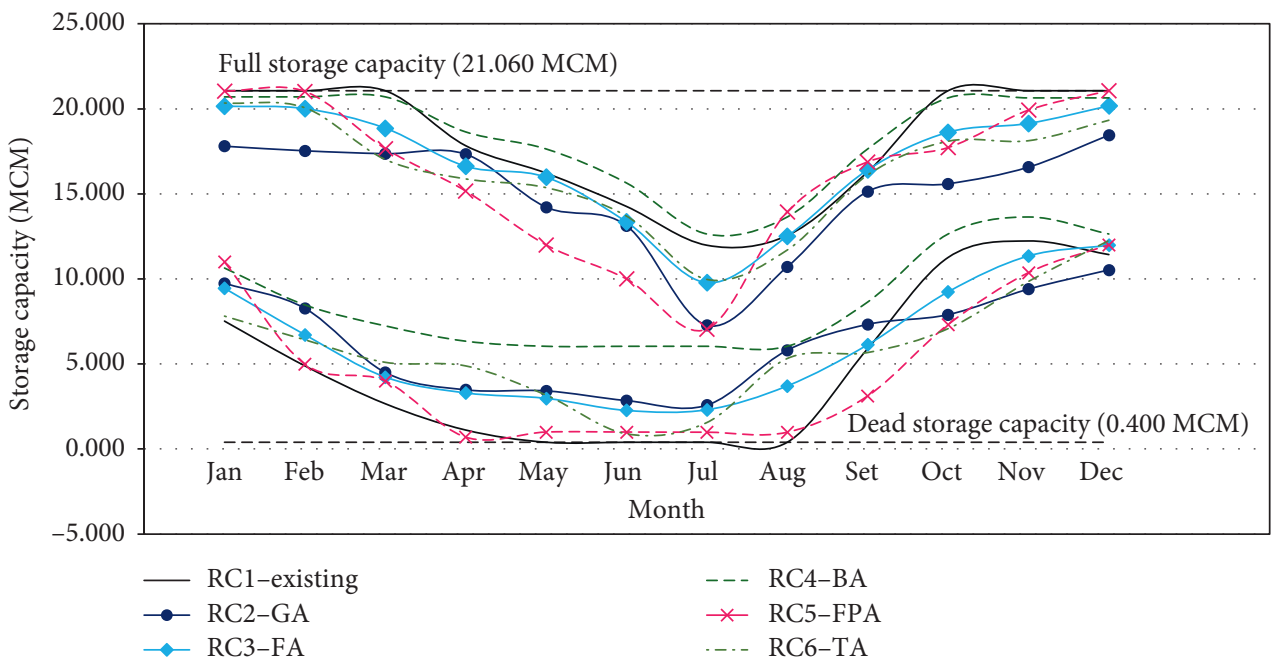

FIgURE 10: Optimal rule curves of the Huay Ling Jone reservoir. 


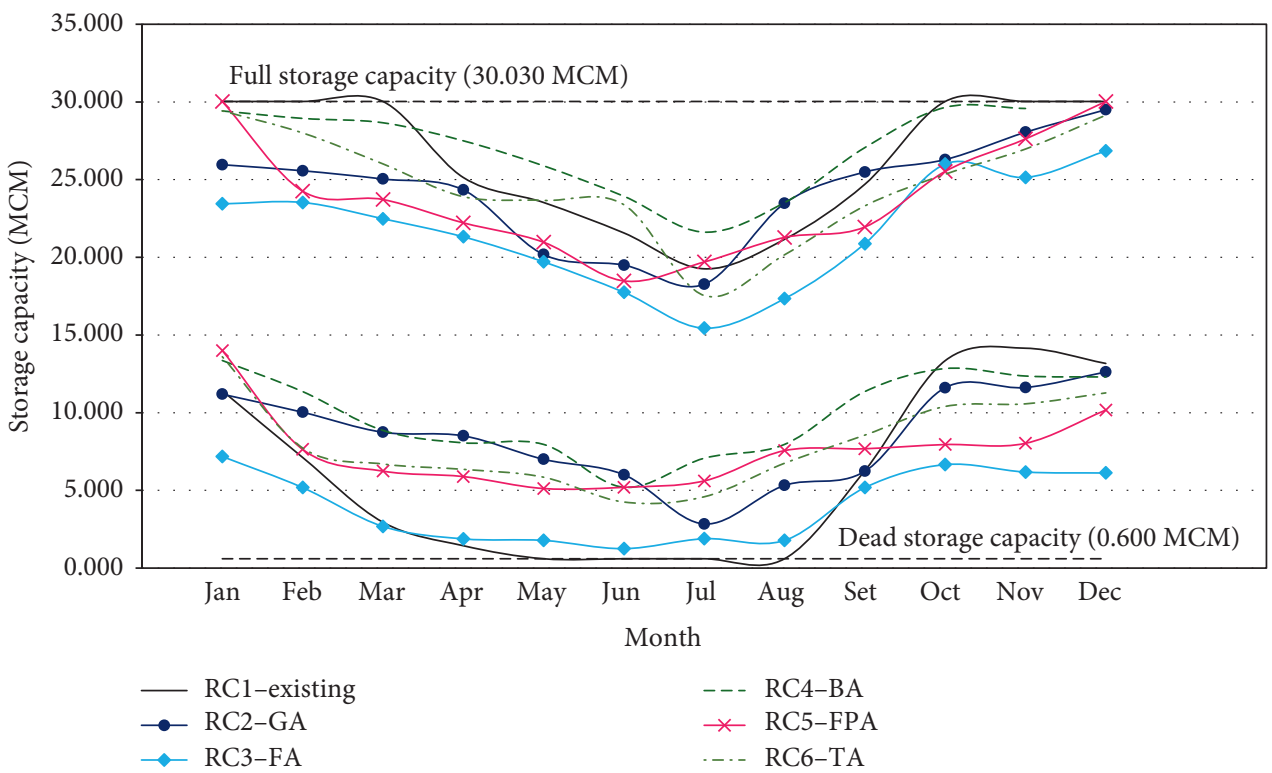

FIgURE 11: Optimal rule curves of the Huay Sabag reservoir.

TABLE 1: Situations of water shortage and excess release of the Huay Ling Jone reservoir using historic inflow of 24 years.

\begin{tabular}{|c|c|c|c|c|c|c|}
\hline \multirow[t]{2}{*}{ Situations } & \multirow[t]{2}{*}{ Rule curves } & \multirow[t]{2}{*}{ Frequency (times/year) } & \multicolumn{2}{|c|}{$\begin{array}{c}\text { Volume } \\
\text { (million cubic meter) }\end{array}$} & \multicolumn{2}{|c|}{ Time period (year) } \\
\hline & & & Average & Maximum & Average & Maximum \\
\hline \multirow{6}{*}{ Shortage } & RC1-Existing & 0.792 & 4.917 & 12.000 & 3.800 & 8.000 \\
\hline & RC2-GA & 0.542 & 2.250 & 11.000 & 3.250 & 6.000 \\
\hline & RC3-FA & 0.542 & 1.917 & 10.000 & 2.600 & 3.000 \\
\hline & RC4-BA & 0.458 & 2.167 & 11.000 & 2.200 & 3.000 \\
\hline & RC5-FPA & 0.875 & 3.792 & 11.000 & 7.000 & 14.000 \\
\hline & RC6-TA & 0.750 & 2.542 & 9.000 & 6.000 & 13.000 \\
\hline \multirow{6}{*}{ Excess water } & RC1-Existing & 0.958 & 9.191 & 15.857 & 11.500 & 22.000 \\
\hline & RC2-GA & 0.917 & 6.684 & 13.705 & 7.333 & 14.000 \\
\hline & RC3-FA & 0.833 & 6.214 & 13.705 & 5.000 & 12.000 \\
\hline & RC4-BA & 0.875 & 6.484 & 13.705 & 5.250 & 12.000 \\
\hline & RC5-FPA & 0.958 & 8.146 & 15.770 & 11.500 & 14.000 \\
\hline & RC6-TA & 0.917 & 6.995 & 13.705 & 7.333 & 14.000 \\
\hline
\end{tabular}

TABLE 2: Situations of water shortage and excess release of the Huay Ling Jone reservoir using synthetic inflow of 1,000 events.

\begin{tabular}{|c|c|c|c|c|c|c|c|}
\hline \multirow[t]{2}{*}{ Situations } & \multirow[t]{2}{*}{ Rule curves } & & \multirow[t]{2}{*}{ Frequency (times/year) } & \multicolumn{2}{|c|}{$\begin{array}{c}\text { Volume } \\
\text { (million cubic meter) }\end{array}$} & \multicolumn{2}{|c|}{ Time period (year) } \\
\hline & & & & Average & Maximum & Average & Maximum \\
\hline \multirow{12}{*}{ Shortage } & \multirow{2}{*}{ RC1-Existing } & $\mu$ & 0.717 & 4.599 & 10.819 & 5.388 & 9.433 \\
\hline & & $\sigma$ & 0.136 & 1.041 & 2.504 & 3.420 & 4.072 \\
\hline & \multirow{2}{*}{ RC2-GA } & $\mu$ & 0.532 & 2.640 & 10.517 & 3.852 & 6.500 \\
\hline & & $\sigma$ & 0.148 & 0.978 & 2.935 & 2.080 & 2.951 \\
\hline & \multirow{2}{*}{ RC3-FA } & $\mu$ & 0.498 & 2.217 & 9.633 & 3.649 & 6.079 \\
\hline & & $\sigma$ & 0.148 & 0.932 & 2.974 & 1.950 & 2.845 \\
\hline & \multirow{2}{*}{$\mathrm{RC} 4-\mathrm{BA}$} & $\mu$ & 0.513 & 2.532 & 10.432 & 3.615 & 6.111 \\
\hline & & $\sigma$ & 0.147 & 0.964 & 2.804 & 1.958 & 2.807 \\
\hline & \multirow{2}{*}{ RC5-FPA } & $\mu$ & 0.737 & 3.573 & 10.384 & 5.952 & 10.155 \\
\hline & & $\sigma$ & 0.137 & 0.968 & 2.342 & 3.752 & 4.336 \\
\hline & \multirow{2}{*}{ RC6-TA } & $\mu$ & 0.640 & 2.781 & 9.922 & 4.663 & 8.184 \\
\hline & & $\sigma$ & 0.143 & 0.956 & 2.572 & 2.709 & 3.624 \\
\hline
\end{tabular}


TABle 2: Continued.

\begin{tabular}{|c|c|c|c|c|c|c|c|}
\hline \multirow[t]{2}{*}{ Situations } & \multirow[t]{2}{*}{ Rule curves } & & \multirow[t]{2}{*}{ Frequency (times/year) } & \multicolumn{2}{|c|}{$\begin{array}{c}\text { Volume } \\
\text { (million cubic meter) }\end{array}$} & \multicolumn{2}{|c|}{ Time period (year) } \\
\hline & & & & Average & Maximum & Average & Maximum \\
\hline \multirow{12}{*}{ Excess water } & \multirow{2}{*}{ RC1-Existing } & $\mu$ & 0.958 & 9.621 & 15.725 & 15.902 & 19.105 \\
\hline & & $\sigma$ & 0.046 & 1.525 & 0.509 & 7.156 & 4.985 \\
\hline & \multirow{2}{*}{ RC2-GA } & $\mu$ & 0.861 & 7.796 & 15.564 & 7.684 & 12.702 \\
\hline & & $\sigma$ & 0.077 & 1.719 & 0.872 & 4.800 & 4.883 \\
\hline & \multirow{2}{*}{ RC3-FA } & $\mu$ & 0.813 & 7.299 & 15.489 & 6.360 & 11.265 \\
\hline & & $\sigma$ & 0.092 & 1.810 & 1.048 & 4.007 & 4.529 \\
\hline & \multirow{2}{*}{ RC4-BA } & $\mu$ & 0.836 & 7.527 & 15.569 & 6.894 & 11.895 \\
\hline & & $\sigma$ & 0.083 & 1.750 & 0.926 & 4.324 & 4.738 \\
\hline & \multirow{2}{*}{ RC5-FPA } & $\mu$ & 0.937 & 8.658 & 15.642 & 12.947 & 17.170 \\
\hline & & $\sigma$ & 0.052 & 1.642 & 0.702 & 6.881 & 5.132 \\
\hline & \multirow{2}{*}{ RC6-TA } & $\mu$ & 0.882 & 7.952 & 15.608 & 8.662 & 13.678 \\
\hline & & $\sigma$ & 0.071 & 1.693 & 0.836 & 5.292 & 4.988 \\
\hline
\end{tabular}

Note. $\mu=$ average; $\sigma=$ standard deviation.

TABLE 3: Situations of water shortage and excess release of the Huay Sabag reservoir using historic inflow of 22 years.

\begin{tabular}{|c|c|c|c|c|c|c|}
\hline \multirow[t]{2}{*}{ Situations } & \multirow[t]{2}{*}{ Rule curves } & \multirow[t]{2}{*}{ Frequency (times/year) } & \multicolumn{2}{|c|}{$\begin{array}{l}\text { Volume (million cubic } \\
\text { meter) }\end{array}$} & \multicolumn{2}{|c|}{ Time period (year) } \\
\hline & & & Average & Maximum & Average & Maximum \\
\hline \multirow{6}{*}{ Shortage } & RC1-Existing & 0.000 & 0.000 & 0.000 & 0.000 & 0.000 \\
\hline & RC2-GA & 0.000 & 0.000 & 0.000 & 0.000 & 0.000 \\
\hline & RC3-FA & 0.000 & 0.000 & 0.000 & 0.000 & 0.000 \\
\hline & RC4-BA & 0.000 & 0.000 & 0.000 & 0.000 & 0.000 \\
\hline & RC5-FPA & 0.000 & 0.000 & 0.000 & 0.000 & 0.000 \\
\hline & RC6-TA & 0.000 & 0.000 & 0.000 & 0.000 & 0.000 \\
\hline \multirow{6}{*}{ Excess water } & RC1-Existing & 1.000 & 3.991 & 3.991 & 22.000 & 22.000 \\
\hline & RC2-GA & 1.000 & 3.159 & 3.159 & 22.000 & 22.000 \\
\hline & RC3-FA & 1.000 & 3.159 & 3.159 & 22.000 & 22.000 \\
\hline & $\mathrm{RC} 4-\mathrm{BA}$ & 1.000 & 3.159 & 3.159 & 22.000 & 22.000 \\
\hline & RC5-FPA & 1.000 & 3.159 & 3.159 & 22.000 & 22.000 \\
\hline & RC6-TA & 1.000 & 3.159 & 3.159 & 22.000 & 22.000 \\
\hline
\end{tabular}

TABLe 4: Situations of water shortage and excess release of the Huay Sabag reservoir using synthetic inflow of 1,000 events.

\begin{tabular}{|c|c|c|c|c|c|c|c|}
\hline \multirow[t]{2}{*}{ Situations } & \multirow[t]{2}{*}{ Rule curves } & & \multirow{2}{*}{ Frequency (times/year) } & \multicolumn{2}{|c|}{$\begin{array}{c}\text { Volume } \\
\text { (million cubic meter) }\end{array}$} & \multicolumn{2}{|c|}{ Time period (year) } \\
\hline & & & & Average & Maximum & Average & Maximum \\
\hline \multirow{12}{*}{ Shortage } & \multirow{2}{*}{ RC1-Existing } & $\mu$ & 0.000 & 0.000 & 0.000 & 0.000 & 0.000 \\
\hline & & $\sigma$ & 0.000 & 0.000 & 0.000 & 0.000 & 0.000 \\
\hline & \multirow{2}{*}{ RC2-GA } & $\mu$ & 0.000 & 0.000 & 0.000 & 0.000 & 0.000 \\
\hline & & $\sigma$ & 0.000 & 0.000 & 0.000 & 0.000 & 0.000 \\
\hline & \multirow{2}{*}{ RC3-FA } & $\mu$ & 0.000 & 0.000 & 0.000 & 0.000 & 0.000 \\
\hline & & $\sigma$ & 0.000 & 0.000 & 0.000 & 0.000 & 0.000 \\
\hline & \multirow{2}{*}{ RC4-BA } & $\mu$ & 0.000 & 0.000 & 0.000 & 0.000 & 0.000 \\
\hline & & $\sigma$ & 0.000 & 0.000 & 0.000 & 0.000 & 0.000 \\
\hline & \multirow{2}{*}{ RC5-FPA } & $\mu$ & 0.000 & 0.000 & 0.000 & 0.000 & 0.000 \\
\hline & & $\sigma$ & 0.000 & 0.000 & 0.000 & 0.000 & 0.000 \\
\hline & \multirow{2}{*}{ RC6-TA } & $\mu$ & 0.000 & 0.000 & 0.000 & 0.000 & 0.000 \\
\hline & & $\sigma$ & 0.000 & 0.000 & 0.000 & 0.000 & 0.000 \\
\hline
\end{tabular}


TABle 4: Continued.

\begin{tabular}{|c|c|c|c|c|c|c|c|}
\hline \multirow[t]{2}{*}{ Situations } & \multirow[t]{2}{*}{ Rule curves } & & \multirow[t]{2}{*}{ Frequency (times/year) } & \multicolumn{2}{|c|}{$\begin{array}{c}\text { Volume } \\
\text { (million cubic meter) }\end{array}$} & \multicolumn{2}{|c|}{ Time period (year) } \\
\hline & & & & Average & Maximum & Average & Maximum \\
\hline \multirow{12}{*}{ Excess water } & \multirow{2}{*}{ RC1-Existing } & $\mu$ & 1.000 & 3.990 & 3.991 & 22.000 & 22.000 \\
\hline & & $\sigma$ & 0.000 & 0.005 & 0.000 & 0.000 & 0.000 \\
\hline & \multirow{2}{*}{ RC2-GA } & $\mu$ & 1.000 & 3.159 & 3.159 & 22.000 & 22.000 \\
\hline & & $\sigma$ & 0.000 & 0.000 & 0.000 & 0.000 & 0.000 \\
\hline & \multirow{2}{*}{ RC3-FA } & $\mu$ & 1.000 & 3.159 & 3.159 & 22.000 & 22.000 \\
\hline & & $\sigma$ & 0.000 & 0.000 & 0.000 & 0.000 & 0.000 \\
\hline & \multirow{2}{*}{ RC4-BA } & $\mu$ & 1.000 & 3.159 & 3.159 & 22.000 & 22.000 \\
\hline & & $\sigma$ & 0.000 & 0.003 & 0.000 & 0.000 & 0.000 \\
\hline & \multirow{2}{*}{ RC5-FPA } & $\mu$ & 1.000 & 3.159 & 3.159 & 22.000 & 22.000 \\
\hline & & $\sigma$ & 0.000 & 0.000 & 0.000 & 0.000 & 0.000 \\
\hline & \multirow{2}{*}{ RC6-TA } & $\mu$ & 1.000 & 3.159 & 3.159 & 22.000 & 22.000 \\
\hline & & $\sigma$ & 0.000 & 0.001 & 0.000 & 0.000 & 0.000 \\
\hline
\end{tabular}

Note. $\mu=$ average; $\sigma=$ standard deviation.

TABLE 5: Situations of water shortage and excess release of the Huay Sabag reservoir using historic inflow of 22 years (increasing $30 \%$ of water demand).

\begin{tabular}{|c|c|c|c|c|c|c|}
\hline \multirow[t]{2}{*}{ Situations } & \multirow{2}{*}{ Rule curves } & \multirow{2}{*}{ Frequency (times/year) } & \multicolumn{2}{|c|}{$\begin{array}{c}\text { Volume } \\
\text { (million cubic meter) }\end{array}$} & \multicolumn{2}{|c|}{ Time period (year) } \\
\hline & & & Average & Maximum & Average & Maximum \\
\hline \multirow{6}{*}{ Shortage } & RC1-Existing & 0.955 & 1.909 & 2.000 & 21.000 & 21.000 \\
\hline & RC2-GA & 1.000 & 3.000 & 3.000 & 22.000 & 22.000 \\
\hline & RC3-FA & 1.000 & 3.000 & 3.000 & 22.000 & 22.000 \\
\hline & RC4-BA & 1.000 & 3.000 & 3.000 & 22.000 & 22.000 \\
\hline & RC5-FPA & 1.000 & 2.955 & 3.000 & 22.000 & 22.000 \\
\hline & RC6-TA & 1.000 & 3.000 & 3.000 & 22.000 & 22.000 \\
\hline \multirow{6}{*}{ Excess water } & RC1-Existing & 1.000 & 3.338 & 3.338 & 22.000 & 22.000 \\
\hline & RC2-GA & 1.000 & 2.638 & 2.638 & 22.000 & 22.000 \\
\hline & RC3-FA & 1.000 & 2.638 & 2.638 & 22.000 & 22.000 \\
\hline & RC4-BA & 1.000 & 2.638 & 2.638 & 22.000 & 22.000 \\
\hline & RC5-FPA & 1.000 & 2.638 & 2.638 & 22.000 & 22.000 \\
\hline & RC6-TA & 1.000 & 2.638 & 2.638 & 22.000 & 22.000 \\
\hline
\end{tabular}

TABLE 6: Situations of water shortage and excess release of the Huay Sabag reservoir using synthetic inflow of 1,000 events (increasing $30 \%$ of water demand).

\begin{tabular}{|c|c|c|c|c|c|c|c|}
\hline \multirow[t]{2}{*}{ Situations } & \multirow[t]{2}{*}{ Rule curves } & & \multirow[t]{2}{*}{ Frequency (times/year) } & \multicolumn{2}{|c|}{$\begin{array}{c}\text { Volume } \\
\text { (million cubic meter) }\end{array}$} & \multicolumn{2}{|c|}{ Time period (year) } \\
\hline & & & & Average & Maximum & Average & Maximum \\
\hline \multirow{12}{*}{ Shortage } & \multirow{2}{*}{ RC1-Existing } & $\mu$ & 0.949 & 1.897 & 2.000 & 20.849 & 20.874 \\
\hline & & $\sigma$ & 0.017 & 0.035 & 0.000 & 0.719 & 0.393 \\
\hline & \multirow{2}{*}{ RC2-GA } & $\mu$ & 1.000 & 3.000 & 3.000 & 21.977 & 21.996 \\
\hline & & $\sigma$ & 0.002 & 0.006 & 0.000 & 0.514 & 0.089 \\
\hline & \multirow{2}{*}{ RC3-FA } & $\mu$ & 1.000 & 3.000 & 3.000 & 22.000 & 22.000 \\
\hline & & $\sigma$ & 0.000 & 0.000 & 0.000 & 0.000 & 0.000 \\
\hline & \multirow{2}{*}{ RC4-BA } & $\mu$ & 1.000 & 2.999 & 3.000 & 21.885 & 21.979 \\
\hline & & $\sigma$ & 0.004 & 0.014 & 0.000 & 1.145 & 0.211 \\
\hline & \multirow{2}{*}{ RC5-FPA } & $\mu$ & 1.000 & 2.954 & 3.000 & 21.977 & 21.996 \\
\hline & & $\sigma$ & 0.002 & 0.010 & 0.000 & 0.514 & 0.089 \\
\hline & \multirow{2}{*}{ RC6-TA } & $\mu$ & 1.000 & 2.999 & 3.000 & 21.931 & 21.987 \\
\hline & & $\sigma$ & 0.003 & 0.012 & 0.000 & 0.889 & 0.170 \\
\hline
\end{tabular}


TABLE 6: Continued.

\begin{tabular}{|c|c|c|c|c|c|c|c|}
\hline \multirow[t]{2}{*}{ Situations } & \multirow[t]{2}{*}{ Rule curves } & & \multirow[t]{2}{*}{ Frequency (times/year) } & \multicolumn{2}{|c|}{$\begin{array}{c}\text { Volume } \\
\text { (million cubic meter) }\end{array}$} & \multicolumn{2}{|c|}{ Time period (year) } \\
\hline & & & & Average & Maximum & Average & Maximum \\
\hline \multirow{12}{*}{ Excess water } & \multirow{2}{*}{ RC1-Existing } & $\mu$ & 1.000 & 3.337 & 3.338 & 22.000 & 22.000 \\
\hline & & $\sigma$ & 0.000 & 0.006 & 0.000 & 0.000 & 0.000 \\
\hline & \multirow{2}{*}{ RC2-GA } & $\mu$ & 1.000 & 2.638 & 2.638 & 22.000 & 22.000 \\
\hline & & $\sigma$ & 0.000 & 0.000 & 0.000 & 0.000 & 0.000 \\
\hline & \multirow{2}{*}{ RC3-FA } & $\mu$ & 1.000 & 2.638 & 2.638 & 22.000 & 22.000 \\
\hline & & $\sigma$ & 0.000 & 0.000 & 0.000 & 0.000 & 0.000 \\
\hline & \multirow{2}{*}{ RC4-BA } & $\mu$ & 1.000 & 2.638 & 2.638 & 22.000 & 22.000 \\
\hline & & $\sigma$ & 0.000 & 0.002 & 0.000 & 0.000 & 0.000 \\
\hline & \multirow{2}{*}{ RC5-FPA } & $\mu$ & 1.000 & 2.638 & 2.638 & 22.000 & 22.000 \\
\hline & & $\sigma$ & 0.000 & 0.000 & 0.000 & 0.000 & 0.000 \\
\hline & \multirow{2}{*}{ RC6-TA } & $\mu$ & 1.000 & 2.638 & 2.638 & 22.000 & 22.000 \\
\hline & & $\sigma$ & 0.000 & 0.001 & 0.000 & 0.000 & 0.000 \\
\hline
\end{tabular}

Note. $\mu=$ average; $\sigma=$ standard deviation.

\section{Conclusion}

This examination proposed the improvement systems associated with the store reenactment model for the inquiry of the ideal guideline bends in the little supply in Thailand. The examination result confirms that the examples of these standard bends were comparable since the regular inflow impact and looking through conditions were equivalent. The examination additionally discovered that the obtained standard bends from the proposed GA, FA, BA, FPA, and TS procedures at the Huay Ling Jone store can relieve the water lack and extreme water circumstances superior to anything utilizing the current principle bends in the two situations. It tends to be presumed that the proposed procedures are reasonable for looking through the ideal guideline bends of the Huay Ling Jone repository where the complete inflow and the all-out-interest are near each other. Moreover, the acquired standard bends of the Huay Sabag utilizing the proposed strategy can all more likely moderate just over the top water circumstance than the current guideline bends in the noteworthy inflow situation and manufactured inflow situation just as with $30 \%$ expansion of water request. The circumstances of water lack of the Huay Sabag utilizing the current principle bends were not as much as utilizing the acquired standard bends of GA, FA, BA, FPA, and TS.

\section{Data Availability}

The data used to support the findings of this study are available from the corresponding author upon request.

\section{Conflicts of Interest}

The authors declare that there are no conflicts of interest regarding the publication of this paper.

\section{Acknowledgments}

This research project was financially supported by Mahasarakham University.

\section{References}

[1] T. Cuvelier, P. Archambeau, B. Dewals, and Q. Louveaux, "Comparison between robust and stochastic optimisation for long-term reservoir management under uncertainty," Water Resources Management, vol. 32, no. 5, pp. 1599-1614, 2018.

[2] S. K. Jain, M. K. Goel, and P. K. Agarwal, "Reservoir operation studies of sabarmati system, India," Journal of Water Resources Planning and Management, vol. 124, no. 1, pp. 31-37, 1998.

[3] X. Li, S. Guo, P. Liu, and G. Chen, "Dynamic control of flood limited water level for reservoir operation by considering inflow uncertainty," Journal of Hydrology, vol. 391, no. 1-2, pp. 124-132, 2010.

[4] M. E. P. Maceira and M. V. F. Pereira, "Analytical modeling of chronological reservoir operation in probabilistic production costing [of hydrothermal power systems]," IEEE Transactions on Power Systems, vol. 11, no. 1, pp. 171-180, 1996.

[5] M. Jahandideh-Tehrani, O. Bozorg-Haddad, and H. A. Loáiciga, "A review of applications of animal-inspired evolutionary algorithms in reservoir operation modelling," Water and Environment Journal, vol. 35, no. 2, pp. 628-646, 2020.

[6] H. Macian-Sorribes and M. Pulido-Velazquez, "Inferring efficient operating rules in multireservoir water resource systems: a review," Wires Water, vol. 7, no. 1, 2020.

[7] T. D. Dang, A. F. M. K. Chowdhury, and S. Galelli, "On the representation of water reservoir storage and operations in large-scale hydrological models: implications on model parameterization and climate change impact assessments," Hydrology and Earth System Sciences, vol. 24, no. 1, pp. 397-416, 2020.

[8] S. N. Ciolofan, G. Militaru, A. Draghia, R. Drobot, and M. Dragoicea, "Optimization of water reservoir operation to minimize the economic losses caused by pollution," IEEE Access, vol. 6, Article ID 67562, 2018.

[9] K. Voudouris, M. Polemio, A. Sifaleras, and N. Kazakis, "An agricultural decision support system for optimal land use regarding groundwater vulnerability," International Journal of Information Systems and Social Change, vol. 1, no. 4, pp. 66-79, 2010.

[10] C. Chaleeraktrakoon and A. Kangrang, "Dynamic programming with the principle of progressive optimality for 
searching rule curves," Canadian Journal of Civil Engineering, vol. 34, pp. 170-176, 2007.

[11] F. J. Chang, L. Chen, and L. C. Chang, "Optimizing the reservoir operating rule curves by genetic algorithms," $\mathrm{Hy}$ drological Processes, vol. 19, pp. 2277-2289, 2005.

[12] C. H. Yeh, "Applying multi-objective genetic algorithms for planning of flood detention dams system," Taiwan Water Conservancy, vol. 45, no. 2, pp. 70-81, 1997.

[13] A. Tayebiyan, T. A. M. Ali, A. H. Ghazali, and M. A. Malek, "Optimization of exclusive release policies for hydropower reservoir operation by using genetic algorithm," Water Resources Management, vol. 30, pp. 1203-1216, 2016.

[14] A. Kangrang, S. Compliew, and R. Hormwichian, "Optimal reservoir rule curves using simulated annealing," Proceedings of the Institution of Civil Engineers - Water Management, vol. 164, no. 1, pp. 27-34, 2011.

[15] C. R. Suribabu, "Particle swarm optimisation techniques for deriving operation policies for maximum hydropower generation: a case study," International Journal of Ecology \& Development, vol. 4, no. 1, pp. 68-85, 2006.

[16] M. H. Afshar, "Extension of the constrained particle swarm optimization algorithm to optimal operation of multi-reservoirs system," International Journal of Electrical Power and Energy System, vol. 55, pp. 71-81, 2013.

[17] A. Kangrang, W. Pakoktom, W. Nualnukul, and C. Chaleeraktrakoon, "Adaptive reservoir rule curves by optimization and simulation," Proceedings of the Institution of Civil Engineers - Water Management, vol. 170pp. 219-230, 5, 2017.

[18] B. Ming, J.-X. Chang, Q. Huang, Y.-M. Wang, and S.-Z. Huang, "Optimal operation of multi-reservoir system based on cuckoo search algorithm," Water Resources Management, vol. 29, no. 15, pp. 5671-5687, 2015.

[19] U. Faigle and W. Kern, "Some convergence results for probabilistic tabu search," ORSA Journal on Computing, vol. 4, no. 1, pp. 32-37, 1992.

[20] M. D. C. Cunha and L. Ribeiro, "Tabu search algorithms for water network optimization," European Journal of Operational Research, vol. 157, pp. 746-758, 2004.

[21] A. Kangrang, H. Prasanchum, and R. Hormwichian, "Development of future rule curves for multipurpose reservoir operation using conditional genetic and tabu search algorithms," Advances in Civil Engineering, vol. 2018, Article ID 6474870, 10 pages, 2018.

[22] F. Ares, S. R. Rengarajan, E. Villaneuva, E. Skochinski, and E. Moreno, "Application of genetic algorithms and simulated annealing technique in optimising the aperture distributions of antenna array patterns," Electronics Letters, vol. 32, no. 3, pp. 148-149, 1996.

[23] J. Yang, S. Yang, and P. Ni, “A vector tabu search algorithm with enhanced searching ability for pareto solutions and its application to multiobjective optimizations," IEEE Transactions on Magnetics, vol. 52, no. 3, 2016.

[24] A. Pathak, K. VS. Jogender, and A. Banerjee, "Evaluation of reverse ellitism firefly algorithm on the CEC2013 real parameter single objective optimization benchmark functions," in Proceedings of the Electrical Electronics and Computer Engineering (UPCON) 2018 5th IEEE Uttar Pradesh Section International Conference on, pp. 1-6, Gorakhpur, India, November 2018.

[25] X. S. Yang, "Firefly algorithm lévy flights and global optimization," in Research and Development in Intelligent Systems $X X V I$, M. Bramer, R. Ellis, and M. Petridis, Eds., Springer, Berlin, Germany, 2010.
[26] A. Yelghi and C. Köse, “A modified firefly algorithm for global minimum optimization," Applied Soft Computing, vol. 62, pp. 29-44, 2018.

[27] C. Wang and X. Chu, "An improved firefly algorithm with specific probability and its engineering application," IEEE Access, vol. 7, Article ID 57424, 2019.

[28] X. S. Yang, "A new metaheuristic Bat-inspired algorithm in nature inspired cooperative strategies for optimization," Part of the Studies in Computational Intelligence Book Series (SCI), vol. 284, pp. 65-74, 2010.

[29] A. Al-Muraeb and H. Abdel-Aty-Zohdy, "Dimensions in the Bat algorithm with adaptive position update (APU-BA) for short Fiber Bragg grating optimal design," in Proceedings of the Aerospace and Electronics Conference (NAECON) and Ohio Innovation Summit (OIS) 2016 IEEE National, pp. 262-265, Dayton, OH, USA, July 2016.

[30] O. Bozorg-Haddad, I. Karimirad, S. Seifollahi-Aghmuni, and H. A. Loáiciga, "Development and application of the bat algorithm for optimizing the operation of reservoir systems," Journal of Water Resources Planning and Management, vol. 141, no. 8, Article ID 04014097, 2015.

[31] X. Huang, P. Li, and Y. Pu, "Amplitude angle modulated bat algorithm with application to zero-one knapsack problem," IEEE Access, vol. 7, Article ID 27957, 2019.

[32] X. S. Yang, M. Karamanoglu, and X. S. He, "Multi-objective flower pollination algorithm for optimization," Procedia Computer Science, vol. 18, pp. 861-868, 2013.

[33] X. S. Yang, Flower Pollination Algorithm in Nature Inspired Optimization Algorithm, Elsevier, Amsterdam, Netherlands, 2014.

[34] R. Salgotra and U. Singh, "Application of mutation operators to flower pollination algorithm," Expert Systems with Applications, vol. 79, pp. 112-129, 2017.

[35] L. Shen, C. Fan, and X. Huang, "Multi-level image thresholding using modified flower pollination algorithm," IEEE Access, vol. 6, Article ID 30508, 2018.

[36] T. T. Nguyen, J. S. Pan, and T. K. Dao, “An improved flower pollination algorithm for optimizing layouts of nodes in wireless sensor network," IEEE Access, vol. 7, Article ID 75985, 2019.

[37] T. R. Neelakanta and K. Sasireka, "Hydropower reservoir operation using standard operating and standard hedging policies," International Journal of Engineering and Technology, vol. 5, no. 2, pp. 1191-1196, 2013.

[38] W. E. Harraki, D. Ouazar, A. Bouziane, and D. Hasnaoui, "Optimization of reservoir operating curves and hedging rules using genetic algorithm with a new objective function and smoothing constraint: application to a multipurpose dam in Morocco," Environmental Monitoring and Assessment, vol. 193, p. 196, 2021.

[39] L. Zhang, L. Liu, X.-S. Yang, and Y. Dai, "A novel hybrid firefly algorithm for global Optimization," PLoS One, vol. 11, no. 9, Article ID e0163230, 2016.

[40] H. Wang, W. Wang, X. Zhou et al., "Firefly algorithm with neighborhood attraction," Information Sciences, vol. 382, pp. 374-387, 2017.

[41] A. Chakri, R. Khelif, M. Benouaret, and X.-S. Yang, "New directional bat algorithm for continuous optimization problems," Expert Systems with Applications, vol. 69, pp. 159-175, 2017.

[42] A. Fouad and X.-Z. Gao, "A novel modified flower pollination algorithm for global optimization," Neural Computing and Applications, vol. 31, pp. 3875-3908, 2019. 
[43] M. Kumar, M. L. Mittal, G. Soni, and D. Joshi, "A tabu search algorithm for simultaneous selection and scheduling of projects". Harmony Search and Nature Inspired Optimization Algorithms," Advances in Intelligent Systems and Computing, vol. 741, pp. 1111-1121, 2019.

[44] C. Chiamsathit, A. J. Adeloye, and B. S. Soundharajan, "Assessing competing policies at Ubonratana reservoir, Thailand," Proceeding of the Institution of Civil Engineering - Water Management, vol. 167, no. 10, pp. 551-560, 2015. 